\title{
Contracampo
}

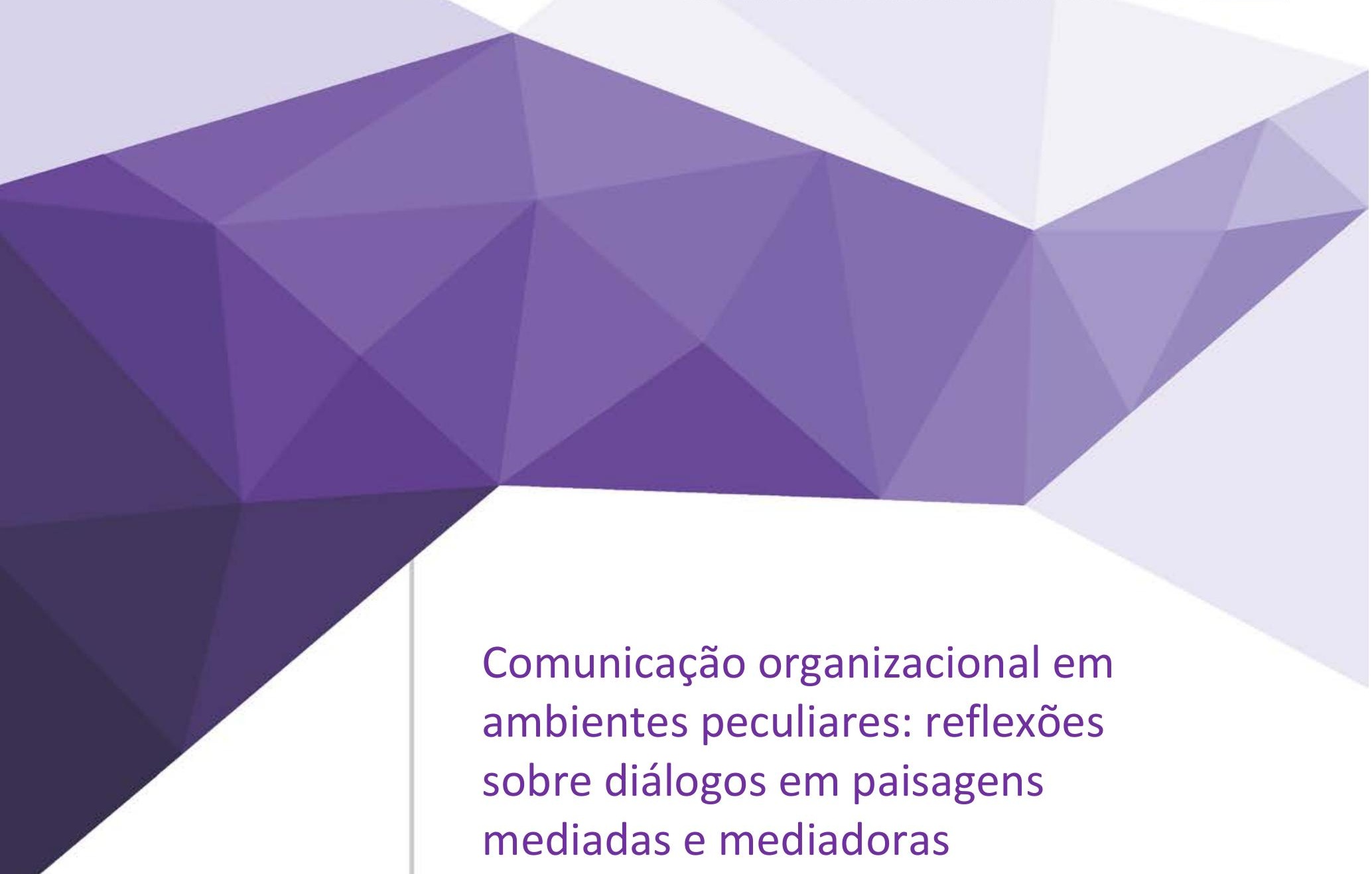

Edição v.36

número 3 / 2017

Contracampo e-ISSN 2238-2577

Niterói (RJ), 36 (3)

dez/2017-mar/2018

A Revista Contracampo é uma revista eletrônica do Programa de Pós-Graduação em Comunicação da Universidade Federal Fluminense e tem como objetivo contribuir para a reflexão crítica em torno do campo midiático, atuando como espaço de circulação da pesquisa e do pensamento acadêmico.

\section{Corporate communication in} peculiar environments: reflections on dialogues in mediated and mediators landscapes

\section{ANA MARIA DANTAS DE MAIO}

Doutora em Comunicação Social pela Universidade Metodista de São Paulo, São Bernardo do Campo, São Paulo, Brasil. Jornalista da Embrapa Pantanal desde 2007. Supervisora do Comitê Local de Publicações da Embrapa Pantanal desde fevereiro de 2017. Brasil. E-mail: anamaio@uol.com.br. ORCID: 0000-00030917-2303

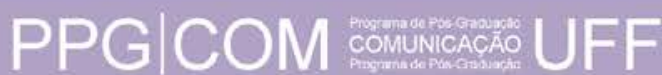

AO CITAR ESTE ARTIGO, UTILIZE A SEGUINTE REFERÊNCIA:

MAIA, Ana Maria Dantas de. Comunicação Organizacional Em Ambientes Peculiares: Reflexões Sobre Diálogos Em Paisagens Mediadas E Mediadoras. Contracampo, Niterói, v. 36, n. 03, pp. 199-218, dez. 2017/ mar. 2018. 


\section{Resumo}

O domínio sobre elementos contextuais, onde ocorrem interações face a face, pode facilitar o planejamento e a execução de programas e ações de comunicação organizacional. Esse diferencial tende a ser mais pronunciado em ambientes considerados peculiares, como os biomas Pantanal e Amazônia, onde o apelo tecnológico é menos evidente. Empresas que atuam nesses locais, e vinculam suas missões ao território, podem explorar de forma profissional e estratégica a comunicação face a face, ainda pouco teorizada pelo campo da comunicação no Brasil. Este artigo investe na identificação de mediações impostas por esse tipo de ambiente e analisa a forma como esses cenários são construídos e mediados pela mídia.

Comunicação organizacional; Comunicação face a face; Pantanal.

\section{Abstract}

The command of contextual elements where face-to-face interactions take place may facilitate the planning and execution of corporate communication actions and organization. This difference tends to be more pronounced in environments that are considered peculiar, such as the Pantanal and Amazon biomes, where technological appeal is less evident. Enterprises that operate in such places and link their missions with the territory can exploit face-to-face communication in a professional and strategic way, which in Brazil is still little explored in the communication field. This article invests in the identification of mediations imposed by this kind of environment and analyzes the way in which these scenarios are built and mediated by the media.

\section{Keywords}

Corporate communication; Face-to-face communication; Pantanal. 


\section{Introdução}

O trabalho de comunicação organizacional em corporações instaladas nos centros urbanos vem sendo continuamente explorado pelos cientistas da área. $A$ análise de cases sobre as práticas comunicacionais nessas empresas subsidia o desenvolvimento teórico do campo das relações públicas e da comunicação organizacional. Um bom exemplo é o crescente número de publicações envolvendo o uso de mídias sociais pelas organizações - uma forma de comunicação bastante disseminada especialmente entre públicos urbanos.

No entanto, há outras nuances da comunicação organizacional ainda pouco exploradas pela pesquisa acadêmica. Os contatos face a face em ambientes peculiares - que agregam paisagens urbanas e rurais em sua essência - carecem de um conhecimento teórico mais aprofundado. É o caso do trabalho desenvolvido por equipes de comunicação de empresas que atuam em biomas como Pantanal e Amazônia, cujas missões se encontram vinculadas ao espaço físico. Os cenários, nesses casos, extrapolam a ideia de serem simplesmente o local de trabalho desses profissionais. Eles impõem especificidades à rotina dos comunicadores que merecem algumas reflexões - tanto pelas circunstâncias como os lugares são mediados pela mídia quanto pelas suas instâncias mediadoras particulares. Explicando melhor, atividades planejadas e executadas no contexto da comunicação organizacional em regiões de rica biodiversidade, como Pantanal e Amazônia, estão submetidas a um duplo viés mediador, ou seja, o conhecimento prévio que os interlocutores envolvidos acumulam sobre o território ainda não visitado e o papel mediador das próprias paisagens incidindo sobre as interações que ocorrem nesses ambientes.

O objetivo desse artigo é identificar algumas mediações que caracterizam o Pantanal como uma paisagem peculiar e que incidem sobre o trabalho de comunicação organizacional desenvolvido nessa região. A vivência desta autora nesse ambiente permitiu a observação de situações singulares, que eventualmente se replicam em outras paisagens de rica biodiversidade, como a Amazônia. A percepção de outros pesquisadores sobre a relação ambiente/comunicação envolvendo a Amazônia é resgatada neste estudo. Os dois biomas se caracterizam como instâncias mediadoras para os diálogos que ocorrem em seus limites geográficos. Especificamente no caso do Pantanal, foi observado que a própria paisagem condiciona o conteúdo e a forma da comunicação face a face ali praticada. Esse tipo de interação - bastante valorizada nesse espaço - apresenta potencial estratégico para a comunicação organizacional e carece de conhecimento teórico que possa nortear e otimizar seu desenvolvimento. 
Esta pesquisa começa com a descrição da metodologia da imersão, contemplada não apenas pela ciência da comunicação, mas especialmente por teóricos da geografia em seus estudos sobre paisagens; apresenta uma fundamentação teórica que destaca autores que conceituam mediações, comunicação organizacional e comunicação face a face; avança para uma breve contextualização sobre o imaginário coletivo construído pela mídia a respeito do Pantanal; identifica instâncias mediadoras da comunicação face a face no Pantanal, baseada em observações obtidas a partir da imersão; e conclui que as condições ambientais e suas mediações precisam ser conhecidas e exploradas adequadamente pela comunicação organizacional executada nesses espaços ${ }^{1}$.

\section{Metodologia da imersão: paisagens e experiências}

\section{partilhadas}

Em função de seu caráter transdisciplinar, a comunicação se aproxima com frequência de outras ciências em busca de contribuições que auxiliem na problematização de fenômenos comunicacionais. Sociologia, linguística, psicologia social, filosofia e outras disciplinas são comumente acionadas por estudiosos da comunicação. Estudos empreendidos no campo da geografia também podem cooperar nesse sentido.

É dessa área de conhecimento que surgem noções agregadoras sobre a concepção de paisagem - conceito que deve ser compreendido nas dimensões rural e urbana. Autores dessa disciplina apontam que as pesquisas sobre um determinado espaço geográfico não podem prescindir da imersão. No campo da comunicação a mesma metodologia parece adequada para alguns estudos sobre a percepção de mediações.

“Por que estudar os significados das paisagens? Porque revelam valores e concepções de mundo, experiências pessoais e processos históricos que estão muito além da forma apreendida pela visualidade mais imediata", pondera Sakaguti Junior (2010, p. 20). O autor explica que a ideia de paisagem não deve se restringir à vista panorâmica ou ao conjunto visual de determinado lugar. Ele faz parte de uma corrente da geografia que entrelaça as paisagens com a cultura, conexão bastante promissora para a pesquisa dos aspectos mediadores inerentes aos espaços físicos.

\footnotetext{
${ }^{1}$ Parte das reflexões desenvolvidas neste artigo integra a tese de doutorado "O papel da comunicação face a face nas organizações no contexto da sociedade midiatizada", defendida por esta autora, em fevereiro de 2016, na Universidade Metodista de São Paulo.
} 
Também representante dessa vertente, Sandeville Junior (2004) vincula paisagem à experiência, desencorajando estudos exclusivamente por via indireta, como imagens e cartografia, e defendendo olhares transdisciplinares para a compreensão dos lugares. De acordo com o geógrafo, devido à natureza da paisagem, a imersão se institui como metodologia capaz de produzir sentidos para seu conhecimento. Sandeville Junior adverte que comum deve ser entendido tanto na concepção de corriqueiro como de coletivo.

O sentido da paisagem não pode ser dado apenas pelo universo teórico e existencial do observador, sob o risco de um estereótipo. $\mathrm{Na}$ verdade, a paisagem é mais intensamente revelada a partir das pessoas que têm nela uma experiência comum (SANDEVILLE JUNIOR, 2004, p. 3).

A ideia de experiência partilhada para a compreensão das paisagens revelase oportuna para decifrar os processos de mediação que envolvem o ambiente físico. Para Sandeville Junior (2004, p. 4), a imersão torna-se válida mesmo para territórios desabitados por humanos, "pois revelará aspectos que não podem ser percebidos por via indireta de bases de dados e leituras de instrumentos".

\begin{abstract}
Basicamente, refiro-me à necessidade de um contato direto, não apenas no nível rudimentar da percepção visual dos objetos que se encontram na paisagem, pois não são em si mesmos formadores da paisagem. Esse contato deve colocar a experiência humana em evidência. Trata-se de reconhecer a paisagem em sua dimensão estética, não de beleza plástica (arranjo formal) ou de utilidade (adequação funcional), mas de uma experiência sensível, que é o modo como usamos o termo estética aqui. A paisagem é uma experiência humana. Desafia, portanto, uma relação de alteridade e descentramento, de revisão de pressupostos, onde somos imensamente renovados por essa experiência, ou seja, se constrói o sentido de uma paisagem partilhada (SANDEVILLE JUNIOR, 2004, p. 4).
\end{abstract}

A proposta metodológica de Sandeville Junior excede os interesses da geografia e oferece suporte para descobertas interessantes no campo da comunicação. Se o espaço físico é reconhecido como experiência humana e se as mediações aqui pesquisadas têm sua essência vinculada à vivência, o deslocamento e a imersão despontam como alternativas viáveis para o estudo das instâncias mediadoras nos processos comunicacionais. Eles tendem a permitir outros tipos de observações.

O autor reforça a importância dessa metodologia por meio de um exemplo similar àqueles fornecidos pelo sociólogo francês Louis Quéré (2010) sobre experiências. Para este autor, o sujeito só saberá exatamente o que é uma maçã ao experimentá-la (por mais que as descrições indiquem sua cor, textura, sabor e 
dimensões). Da mesma forma, Sandeville Junior (2004) sugere que as paisagens só podem ser compreendidas se forem vivenciadas e se houver um envolvimento.

Conforme observa Sakaguti Junior (2010), os vínculos estabelecidos com o espaço físico são responsáveis pela construção de significados especiais atribuídos a ele. Em ambientes notadamente urbanos, onde vive a maioria da população, as mediações parecem menos perceptíveis por estarem incorporadas àquela cotidianidade. Quando ocorre o deslocamento de atores urbanos para o ambiente rural, surge o "estranhamento" relatado por Bianchi (2011, p. 134):

A vivência experimentada em um cotidiano urbano é muito distinta da percebida no contexto rural, são outras temporalidades, outras maneiras de se encarar o trabalho, as relações e, em muitos casos, de se relacionar com os meios de comunicação. É, com certeza, uma relação de "estranhamento" vivida, na qual estão presentes ritualidades e experiências com as quais não se está acostumado.

Assim, os contrastes entre urbano e rural persistem como elementos distintivos das mediações espaciais e serão abordados com mais profundidade adiante. Outra mediação relevante que assume o protagonismo na construção de imaginários é aquela formatada pela mídia e que, na sociedade midiatizada², se estabelece como hegemônica. Nesse sentido, alguns estudiosos - geralmente conhecedores de realidades outras - começam a questionar a coerência entre os lugares apresentados pela mídia e os lugares reais.

Destarte, o indivíduo que conhece espaços como Pantanal e Amazônia exclusivamente por imagens visuais disponibilizadas pela mídia terá uma concepção diferente daquele que se desloca à região, abre as porteiras, sacode nas caminhonetes ou lombos de cavalos e sente a temperatura e o cheiro do local. Esse sujeito constrói outro tipo de imaginação e, certamente, retornará desses lugares com repertório diverso e experiências renovadas, pois se submeteu a outras mediações. Esse raciocínio procura sustentar a escolha da metodologia da imersão como forma privilegiada de observação de fenômenos comunicacionais, especialmente aqueles relacionados aos condicionamentos proporcionados pelo espaço físico. Vale lembrar que a elaboração deste estudo só foi possível em virtude da imersão no ambiente avaliado, em suas dimensões urbana e rural. A pesquisa bibliográfica complementa a metodologia.

\footnotetext{
${ }^{2}$ Na concepção de Martino (2012, p. 222), “em linhas gerais, midiatização pode ser entendida como o conjunto das transformações ocorridas na sociedade contemporânea relacionadas ao desenvolvimento dos meios eletrônicos e virtuais de comunicação". Essa definição pode ser considerada bastante simplista, já que o fenômeno da midiatização não se instala com o aparecimento de meios eletrônicos e digitais. No entanto, é aceitável a compreensão de que o processo de transformação social foi potencializado e acelerado a partir deles. Essa discussão avança na tese de doutorado citada anteriormente.
} 


\section{Comunicação organizacional menos conectada}

“Nenhuma organização consegue, hoje, escapar aos impactos causados pelas novas tecnologias. A não-adaptação poderá levá-la ao obsoletismo e à estagnação", já prenunciava Kunsch (2003, p. 261) no início do século. De fato, a comunicação organizacional depende do uso de tecnologias para suas rotinas, planejamentos, contatos, análises de resultados etc. Essa dependência não significa, no entanto, abdicar de formas mais convencionais e menos conectadas de interação humana, como os diálogos face a face. Não é incomum presenciar em organizações pessoas "conversando" por meio de aparatos técnicos, apesar de compartilharem o mesmo espaço físico.

Em relação ao contexto, há que se considerar que a comunicação
nas organizações, assim como a sociedade, sofre todos os impactos
provocados pela revolução digital. Consequentemente, o modo de
produzir e de veicular as mensagens organizacionais também passa
por profundas transformações. Essa nova dinâmica de
processamento de informações e da comunicação na era digital
altera completamente as formas de relacionamento e o modo de
produzir a comunicação (KUNSCH, 2010, p. 54).

Essa realidade tem atraído a atenção de alguns pesquisadores da área, como Martins (2012) e a própria Kunsch. Ao abordar a comunicação interpessoal que se manifesta por meio de trocas verbais e não-verbais - , a autora a considera "singular, insubstituível, interdependente e intrinsecamente compensadora", além de observar que "as organizações em geral a cultivam pouco ou mesmo deixam de possibilitar um ambiente propício para relacionamentos interpessoais realmente qualitativos nas relações cotidianas de trabalho" (KUNSCH, 2010, p. 56).

Martins (2012), por sua vez, também vem acompanhando o fenômeno e direciona suas pesquisas para o uso estratégico da oralidade na comunicação organizacional. Na visão da autora, a opção pela comunicação face a face determina um diferencial para a gestão da comunicação empresarial.

A presença da tecnologia nos processos internos e externos está posta e bem acolhida, porém as questões humanas é que precisam urgentemente figurar nos níveis mais elevados de discussão gerencial -, e isto poderá ser possível a partir de uma abordagem dialógica da academia com o mercado de trabalho (MARTINS, 2012, p. 218).

Para ela, a comunicação se justifica pela necessidade de estabelecer relacionamentos e, mesmo no contexto organizacional, os interlocutores buscam 
por relações humanas. Nesse aspecto, teóricos da comunicação face a face pontuam que a intermediação dos contatos por objetos técnicos introduz um tom impessoal às interações.

Schutz (1979), por exemplo, concebe o mundo estruturado em termos do alcance real, isto é, do aqui e do agora. Embora essa perspectiva não coincida com o mundo midiatizado, que retém outro tipo de estruturação, a contribuição do autor revela-se expressiva para a constituição do conceito em questão, especialmente por associar o conhecimento indireto à impessoalidade e à necessidade de inferências nem sempre plausíveis.

O pesquisador trata o contato presencial como "relacionamento do Nós", situação que requer dos participantes uma "orientação para o Tu" - diferente da comunicação mediada em que a orientação é para Eles. No entanto, as maiores contribuições do autor para o conceito de comunicação face a face são os ingredientes que ele considera indispensáveis para que o relacionamento do Nós, de fato, se concretize. São eles: uma linguagem comum, capaz de permitir a interpretação de significados compartilhados; a reciprocidade de motivações e a descoberta dos motivos do sujeito com o qual se interage; um sistema de relevâncias similar entre os atores; e, em especial, a atenção dispensada durante o encontro, já que "o participante precisa tornar-se intencionalmente consciente da pessoa que o confronta" (SCHUTZ, 1979, p. 181).

Outro conceito que precisa ser abordado antes de seguir adiante é o de mediação. Cercado por imprecisões e desconfianças, ele pode ser considerado complexo por envolver elementos que circundam o processo comunicacional. $\mathrm{Na}$ concepção latino-americana, a mediação representa o processo de negociação de significados que envolve a recepção de mensagens, baseado em elementos culturais das sociedades onde ocorre. O espaço físico, como parte integrante do contexto onde a comunicação face a face se desenvolve, manifesta seu papel como mediador, condicionando a conduta de emissores e receptores.

Para Martin-Serrano (2010), precursor da Teoria da Mediação Social, a mídia (ele estudou a televisão) exerce um poder mediador perante a audiência ao restringir os códigos de interpretação dos conteúdos transmitidos por meio de mensagens, e não no processo de seleção das mensagens em si.

De acordo com essa hipótese, ao Mediador será possível controlar a visão de mundo oferecida à audiência na televisão, sem necessidade de declarar explicitamente juízos de valor. (...) Existiria uma correspondência entre os juízos de valor sociais - graças aos quais o Mediador alcança o controle - e as relações lógicas, por meio das quais o meio codifica as mensagens (MARTIN SERRANO, 2010, p. 6, tradução nossa). 
O pesquisador espanhol define mediação como "a atividade de controle social que impõe limites ao que poderia ser dito, e às maneiras de dizê-lo, por meio de um sistema de ordem" (MARTIN SERRANO, 1976, p. 180, tradução nossa). O raciocínio vale também para se compreender o papel mediador de espaços físicos. Uma sala, uma paisagem, um barco - por si - não impõem restrições ao comportamento de quem os ocupa. No entanto, sabe-se que há regras sociais (códigos) que preveem determinados tipos de conduta para cada ambiente. Essa concepção é fundamental para entender como e por que alguns espaços acabam formatando a comunicação face a face que neles se desenvolve.

\section{A mídia e a construção do imaginário sobre regiões}

\section{peculiares}

Em publicações didáticas e científicas, o Pantanal brasileiro aparece descrito como uma planície alagável, onde o regime de cheia e de seca regula as condições ambientais, favorecendo a conservação da biodiversidade. Na mídia, especificamente no enquadramento jornalístico, a mesma região tem sido apresentada como santuário ou paraíso ecológico, com destaque para a beleza cênica formada por extensas áreas verdes entrecortadas por pequenas lagoas e habitada por animais selvagens. Já a moldura ficcional revela um Pantanal misterioso, ao mesmo tempo tranquilo e tranquilizante, cenário de romances inocentes vividos por personagens rústicos e marcantes.

As diferentes mediações em torno dessa paisagem se manifestam, assim, como recortes que direcionam a visibilidade e a percepção sobre o ambiente. A verossimilhança presente ou ausente nesses discursos não está em discussão; o que esta seção pretende identificar são as diferentes perspectivas de descrição de um mesmo espaço geográfico, que se estabelecem como referências no imaginário coletivo, a ponto de condicionar quaisquer tipos de ações desenvolvidas naquele território, sejam elas cotidianas ou excepcionais.

A vinculação de ambientes "diferentes" a uma concepção mítica - como a que sustenta a ideia de santuário ecológico - , construída pelo discurso midiático, não é fenômeno recente. Ao estudar as duas Amazônias, a mítica e a real, Schettino (2013) recorre à literatura de ficção para desvendar as descrições mediadas sobre aquele espaço. Sua pesquisa cita obras como as do romancista Gastão Cruls, que, em 1925, escreveu “A Amazônia Misteriosa” e, cinco anos depois, "Amazônia que Eu Vi", relatando, respectivamente, o ambiente imaginado e o vivido. 
Também em 1930, o escritor português Ferreira de Castro, que morou quatro anos na floresta amazônica, publicou "A Selva", obra de ficção ambientada naquele território. Por fim, Schettino (2013) menciona Euclides da Cunha, autor de "Um Paraíso Perdido - ensaios, estudos e pronunciamentos sobre a Amazônia", coletânea de textos produzidos a partir de uma expedição àquela região, em 1904, lançada na década de 1990. De acordo com Schettino (2013, p. 11, destaque no original),

\begin{abstract}
as histórias em quadrinhos desenhados, de fácil leitura e apreensão imediata, os filmes cinematográficos e as telenovelas ocupam-se de construir o imaginário das pessoas, independentemente das diferenças culturais e nacionalidades e capacidade de abstração exigida pelo hermetismo simbólico da palavra. As duas Amazônias jazem confundidas para sempre na profusão de filmes e teleplays produzidos pelo século afora assim como não mais é possível distinguir a verdade da ficção ${ }^{3}$.
\end{abstract}

O viés edênico que abastece a cobertura midiática sobre a Amazônia também é objeto de estudo de Dutra (2001, p. 2), para quem a mídia reproduz ou transforma antigas visões estereotipadas, "de modo especial aquelas que retratam a Amazônia como um lugar paradisíaco e, contraditoriamente, ao mesmo tempo inóspito, no qual coexistiriam a exuberância física da natureza e a invisibilidade humana".

Os estereótipos a que Dutra se refere alimentam igualmente boa parte da narrativa jornalística e ficcional contemporânea sobre o Pantanal. Não é o caso de condenar essas construções imaginárias, já que elas cumprem uma função discursiva. Como bem coloca Lippmann (2010, p. 92), “a renúncia a todos os estereótipos por uma completa inocente aproximação à realidade empobreceria a vida humana".

A percepção mitificada do Pantanal tem sido fomentada pelos veículos de comunicação, especialmente através da mediação de produtos ficcionais. De acordo com Maio (2009, p. 217), “até a década de 1980, a população do restante do país o conhecia menos pelos veículos de comunicação e mais pelas cartilhas e livros didáticos utilizados nas aulas de geografia". O próprio acesso dos meios à região era difícil, o que impedia uma cobertura jornalística regular.

Esse quadro começa a se alterar a partir de uma intervenção da extinta TV Manchete ${ }^{4}$. A novela "Pantanal", exibida pela primeira vez nessa emissora em

\footnotetext{
${ }^{3}$ Conceitos como "verdade" e "real" devem ser tomados em sua subjetividade e caberia uma discussão filosófica a respeito. Este estudo, no entanto, não vai aprofundar esse debate, apenas procura chamar a atenção para a relatividade dessas definições.

${ }^{4} \mathrm{~A}$ emissora carioca, pertencente à família Bloch, se autopromovia com o slogan "O Brasil que o Brasil não conhece passa na Manchete" (BALOGH, 2002, p. 146). Funcionou de 1983 a 1999.
} 
1990, apresenta ao país uma região desconhecida, estranha, misteriosa e mítica, adotando uma narrativa inovadora para a época.

De repente, surge uma telenovela que nitidamente foge dos padrões. Ela traz um outro andamento, um outro tempo, um outro ritmo, assumidamente mais lento, com planos contemplativos de longa duração, focalizando mais paisagens que protagonistas, com tratamento plástico mais elaborado e marcante presença da música (MACHADO e BECKER, 2008, p. 12).

O sucesso chegou a abalar o monopólio da maior emissora aberta de TV do Brasil, a Rede Globo, em horário nobre. Escrita por Benedito Ruy Barbosa e dirigida por Jayme Monjardim, a novela tinha um enredo simples: a história de amor entre a pantaneira Juma Marruá, conhecida por se transformar em onça quando irritada, e Jove, um jovem urbano que vivia com a mãe no Rio de Janeiro, mas decide viajar ao Pantanal para conviver com o pai, o fazendeiro José Leôncio. Lá ele conhece J uma e começa o romance. O protagonismo, no entanto, foi da natureza.

De acordo com Balogh (2002, p. 142), "no tocante à exploração do espaço, a escolha do Pantanal como locação foi de rara felicidade: poucos espaços nos levariam de forma tão veemente ao mito do 'paraíso perdido' quanto esse". A novela foi reprisada em outras duas ocasiões: em 1991 pela própria TV Manchete e em 2008 pelo SBT (Sistema Brasileiro de Televisão).

Para Machado e Becker (2008), a novela transferiu para o imaginário dos telespectadores um discurso poético e edênico sobre o bioma. $O$ ethos do local fica fortemente evidenciado no depoimento que a atriz Cristiana Oliveira, que interpretou a personagem Juma Marruá (Figura 1), concede a Becker:

\footnotetext{
No dia em que eu cheguei no Pantanal eu tive vontade de chorar. Porque o choque é absurdo. O choque do urbano com aquela coisa selvagem, sabe? É muito grande e você se sente desse tamanhinho. Você vê o quanto é insignificante. O Pantanal agora é a minha segunda casa. Eu senti essa necessidade de melhorar como pessoa, de me desenvolver como ser humano. Eu aprendo. Nessa distância toda que estou tendo, eu aprendo a dar valor a muita coisa. Coisas a que eu não dava valor porque estavam todo dia a meu lado, entende? Agora eu dou valor (MACHADO e BECKER, 2008, p. 54).
}

Esse "choque" a que se refere a atriz pode refletir também a ruptura entre o Pantanal idealizado, que compunha seu repertório pessoal antes da visita, e a vivência naquele espaço durante o período de filmagem. Na verdade, não há incoerências marcantes entre o ambiente exibido pela novela e a realidade. "Um trabalho de ficção pode ter quase qualquer grau de fidelidade, e desde que o grau de fidelidade possa ser levado em conta, a ficção não é enganosa" (LIPPMANN, 2010 , p. 30). No entanto, a perspectiva ficcional e a própria produção televisiva 
configuram-se como mediações e restringem as possibilidades de interpretação, como preconiza Martin Serrano (2010).

Figura 1 - Atriz Cristiana Oliveira no papel de Juma Marruá.

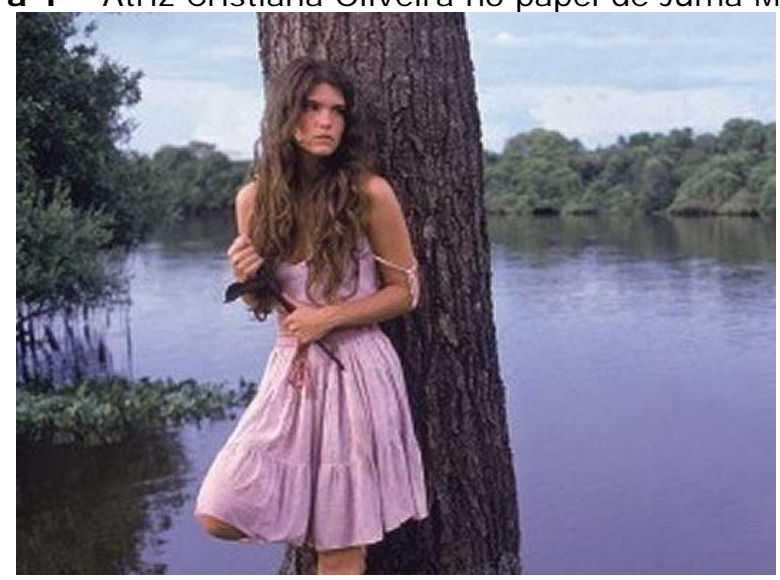

Fonte: UOL Celebridades 5 .

Outra peça ficcional que segue, em parte, a mesma fórmula da novela é o filme "Cabeça a Prêmio", lançado em 2009 e dirigido por Marco Ricca. Apesar de inserida no gênero policial, a trama se desenvolve na região de fronteira do Pantanal brasileiro e se caracteriza por "uma mistura de aclimatação a um ambiente inóspito e desconhecido e uma tranquilidade muito grande na condução de sua narrativa" (VALENTE, 2009).

O estilo poético de narrativa da telenovela e do filme parece ter migrado para outros produtos midiáticos não-ficcionais, como matérias jornalísticas e documentários, e persiste até a atualidade. As editorias mais contempladas em coberturas nacionais são as de meio ambiente, ciência e turismo, com conteúdo muito próximo da ficção - na TV, é comum a exibição de matérias acompanhadas de trilhas sonoras instrumentais ou regionais ilustrando as imagens das belas paisagens.

As características culturais que delimitam aquele espaço e o desenvolvimento tecnológico como diferencial para a sustentação da economia local são algumas das abordagens ausentes ou pouco exploradas pelo jornalismo de grande circulação na cobertura sobre o Pantanal. Certos silenciamentos também são observados por Dutra (2001, p. 2) em relação à Amazônia. "Ao lado de uma Amazônia urbana e moderna subsistem outras amazônias singulares e dotadas de especificidades que as tornam frequentes itens das pautas da mídia, com destaque para a televisão."

A priorização do "exótico" reforça o discurso da imutabilidade, perpetuando - estereótipo de paraísos ecológicos e de ambientes inóspitos tanto para a

5 Disponível em: http://celebridades.uol.com.br/album/2013/10/09/veja-fotos-da-atriz-cristianaoliveira.htm\#fotoNav=3. Acesso em: 23 ago. 2016. 
Amazônia quanto para o Pantanal. As noções de modernidade, de urbanidade e de desenvolvimento soam sempre estranhas para o consumidor de bens simbólicos que não tem a oportunidade de se deslocar até esses territórios.

\section{Elementos mediadores marcantes do Pantanal}

Algumas características próprias da planície pantaneira funcionam como instâncias mediadoras das interações desenvolvidas naquele ambiente. Uma delas é a própria ruralidade, que vem sendo inter-relacionada com a percepção temporal por Bianchi (2011) e outros autores. Dessa forma, o binômio ruralidade/temporalidade distingue uma mediação que incide sobre as propriedades espaciais.

As diferentes temporalidades inscritas no cotidiano de quem habita o meio rural são negociadas e transformam-se em um tempo único, onde está inserido o tempo de trabalho, da família, do descanso e onde o midiático também entra em negociação. A existência de quem vive no meio rural é constantemente marcada pelo tempo de plantar, tempo de colher, tempo de adubar, tempo de sol, tempo de chuva, tempo do trabalho, tempo da casa, tempo midiático. Todos esses tempos apresentam uma existência individual, mas é a junção e suas relações que estabelecem o tempo da vida do sujeito que vive no campo (BIANCHI, 2011, p. 140).

Na urbanidade, os parâmetros temporais também caracterizam o modo de vida, no entanto, esses são elaborados a partir de outras escalas como tempo de congestionamento, tempo na fila de espera, duração da sessão de cinema, horas extras trabalhadas, tempo de download, data de vencimento do cartão de crédito, deadline, entre outras. A intervenção do tempo como elemento de configuração do espaço é semelhante: mudam as variáveis. Além disso, a escassez de moradores em propriedades rurais contribui para uma sensação de monotonia. "As vistas panorâmicas parecem estáticas, despertando uma sensação de imobilidade e inalterabilidade no decorrer do tempo. A impressão é a de que continuariam a ser como são por muito tempo" (SAKAGUTI JUNIOR, 2010, p. 116).

Quando convidados de regiões urbanas visitam espaços rurais, como o Pantanal ou a Amazônia (localizada no extremo norte do Brasil, cf. Figura 2), eles se deparam com esse mecanismo temporal diferenciado e desenvolvem, diante dele, reações de adaptação ou desajuste. A presença de aparelhos transmissores de comunicação de massa, como televisão e rádio, atenua, em parte, a sensação de isolamento/estranhamento. A conexão via internet vai, gradativamente, ocupando esses espaços, garantindo maior familiaridade com o local. 
Se a vista panorâmica transmite a sensação de imutabilidade, no Pantanal ela também se associa à infinitude ou ausência de limites. A própria localização do bioma (Figura 3) - distante dos grandes centros econômicos do país - contribui para essa percepção. Com área de aproximadamente 140 mil quilômetros quadrados, a planície se espalha por dois Estados brasileiros: Mato Grosso (35\%) e Mato Grosso do Sul (65\%).

Figura 2 - Mapa com a localização da Amazônia.

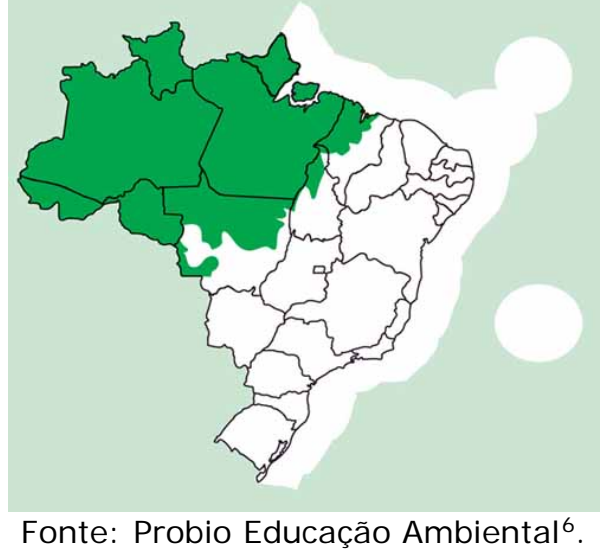

Cerca de 1.400 quilômetros separam, por exemplo, as cidades de São Paulo e Corumbá, no Pantanal sul-mato-grossense, distância que, ao ser percorrida, evoca a noção de grandeza territorial do país. Afora a percepção da distância e da extensão do Pantanal, o simples fato de viver naquele espaço parece imprimir determinadas características aos habitantes.

Figura 3 - Mapa da localização do Pantanal no Brasil.

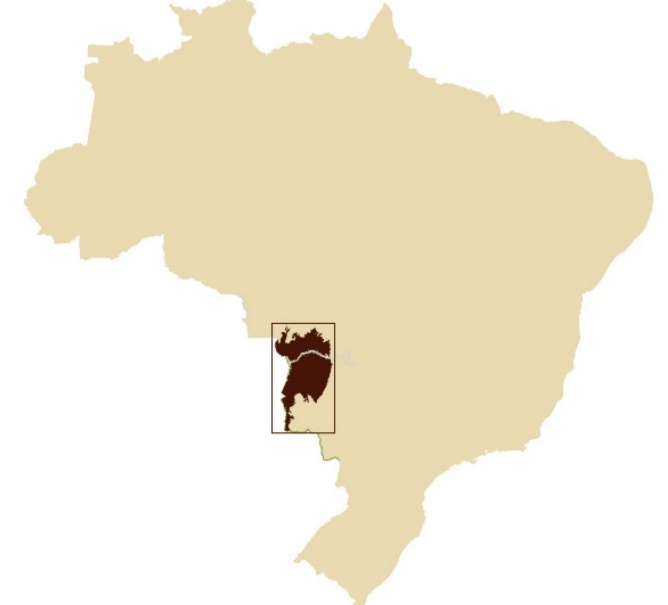

Fonte: Embrapa Pantanal/Geoprocessamento.

\footnotetext{
${ }^{6}$ Disponível em: http://www.ecoa.unb.br/probioea/quia/index.php/amazonia/75-amazonia. Acesso em: 23 ago. 2016.
} 
Embora cada ambiente ou ecossistema possa afetar as pessoas de forma distinta, há, provavelmente, um efeito geral que provoca praticamente as mesmas reações em todos os frequentadores. Quem passa muito tempo no mar, por exemplo, se expõe mais a determinados sentimentos - e a maioria das pessoas sente exatamente esses mesmos "determinados sentimentos"; quem mora no Pantanal tende a falar manso, ser desconfiado e, ao mesmo tempo, solidário; o sujeito que vive na floresta amazônica tem uma índole diferente daquele que vive na mata atlântica (MORAES, 2014). ${ }^{7}$

Existe uma característica própria daquela vista natural que remete à ausência de limites, percebida também pelo poeta Manoel de Barros ao descrever que "no Pantanal não se pode passar régua. Sobremuito quando chove. A régua é existidura de limite. E o Pantanal não tem limites" (BARROS, 1997, p. 29). Essa sensação se relaciona com as amplas áreas de terrenos planos, contínuos, comparáveis ao mar (Figura 4).

Existe um limite real e efetivo na paisagem, mas por alguma característica do ambiente, temos a impressão de que não há limites, que a paisagem não tem fim, que não há horizontes etc., e essa impressão então fica como que permanente. Por exemplo: no mar aberto em que para onde se olhe só se enxerga mar e céu que se confundem como um horizonte contínuo e constante; principalmente após vários dias no mar e sem ver terra. Esse tipo de sensação também ocorre no Pantanal, porque a paisagem, apesar de multivariada, parece ser sempre a mesma; tem-se a impressão de que não há um limite; tem-se a impressão de que não há horizonte (MORAES, 2014).

A percepção da falta de horizontes ou de limites se impõe como elemento físico e psicológico de interferência durante as interações face a face. Há diferenças substanciais entre conversar em ambiente aberto, amplo e indefinido e um diálogo delimitado por paredes. As sensações que podem se associar à comunicação cara a cara no Pantanal são diversas e imprevisíveis, podendo incluir ausência de controle, perda de referências, excesso de informalidade, falta de proteção, de concretude, de concentração e de determinação, entre muitas outras. A descrição da atriz Cristiana Oliveira também pode ser recuperada, particularmente quando ela menciona se sentir pequena diante da imensidão do espaço. Essa projeção diante do ambiente se reflete, de alguma maneira, nas conversas ali desenvolvidas.

\footnotetext{
${ }^{7}$ As contribuições do socioeconomista André Steffens Moraes, ex-pesquisador da Embrapa Pantanal, exmarujo e atual pesquisador da Embrapa Soja (Londrina-PR), foram incorporadas à pesquisa pela perspicácia de suas impressões pessoais sobre a paisagem pantaneira, elaboradas ao longo dos anos em que frequentou aquele ecossistema. Agradeço pela rica colaboração.
} 
Figura 4 - Área da planície pantaneira: horizonte ampliado.

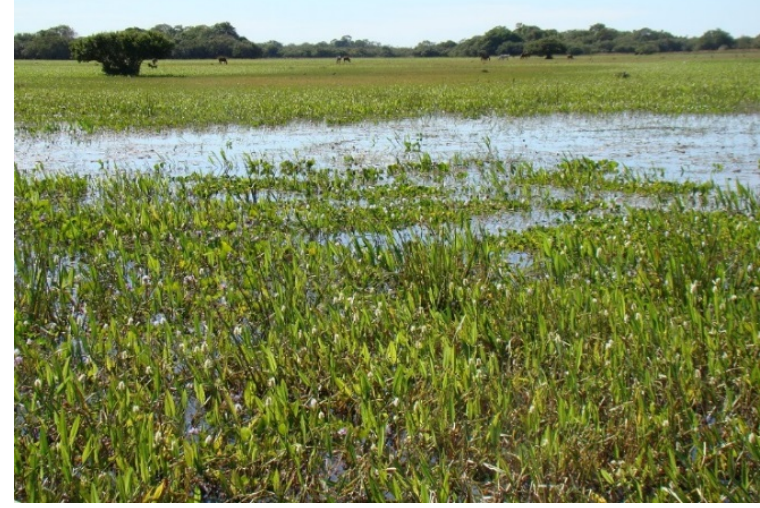

Fonte: Acervo pessoal.

A discussão a respeito do espaço físico levanta também o debate sobre o público e o privado, já que o Pantanal pode ser considerado híbrido: as fazendas são propriedades particulares, pertencentes a uma pessoa física ou jurídica, e o Pantanal enquanto reserva da biosfera, um território de interesse público. Pesquisas desenvolvidas pela Empresa Brasileira de Pesquisa Agropecuária (Embrapa) indicam que $95 \%$ da planície são ocupados por propriedades particulares.

A presença física na região será regida, assim, por códigos mistos de ocupação. Visitantes e anfitriões podem observar nas paisagens a sobreposição de interesses, o público buscando a preservação do território e o privado tentando ampliar os lucros a partir da exploração econômica do local. Esse aparente confronto, até então, se encontra razoavelmente equilibrado devido à operacionalização do conceito de desenvolvimento sustentável. A convivência harmoniosa entre o boi e as espécies selvagens é tida como exemplar desse balanceamento. Essa circunstância também manifesta sua função mediadora, já que os diálogos naquele território rotineiramente tangenciam a questão da sustentabilidade.

A proximidade entre interlocutores e animais selvagens é outro fator que, com frequência, incide sobre as interações. A beleza cênica e a biodiversidade, em geral, encantam os visitantes, que também avistam muitos bois, já que a pecuária de corte é a atividade que mais se adaptou à região. A vegetação e as águas que se

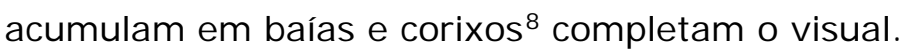

Diante da imprevisibilidade com que os animais podem se aproximar dos humanos, é provável que os diálogos no campo sejam interrompidos para a contemplação ou mesmo para o deslocamento em direção a áreas mais seguras. Observa-se que a presença da fauna provoca alguns tipos de sensações, como

\footnotetext{
${ }^{8}$ Corixos são pequenos rios que se formam em épocas de chuva e desaguam em outros rios maiores.
} 
medo, ansiedade, curiosidade, apreensão, receio etc. Invariavelmente, os animais são temas de conversas ambientadas no Pantanal.

Outros elementos mediadores se apresentam como característicos daquele lugar. O perfil acolhedor dos habitantes da região é um deles. Embora desconfiado, como indicado anteriormente, o homem pantaneiro se distingue pela hospitalidade e solidariedade. Os hábitos culturais dessa população - entre eles as rodas de tereré ${ }^{9}$, as modas de viola e a contação de causos - convidam o visitante a se integrar ao ambiente, conduta reforçada pelo acesso ainda precário às tecnologias da informação. O fenômeno da midiatização, no entanto, tende a alterar essa cotidianidade, impondo outros tipos de mediações.

\section{Considerações finais}

Algumas condições presentes nos espaços físicos parecem, de fato, condicionar o desenvolvimento da comunicação face a face, particularmente os códigos pré-estabelecidos que determinam condutas durante o uso e ocupação de lugares. Regras sociais definem comportamentos típicos para certos ambientes, como permanecer em silêncio durante uma sessão de cinema, um culto em um templo religioso ou uma apresentação de palestra em um auditório. Já em uma partida de futebol, dentro de um estádio, demonstrações de efusividade são esperadas e bem-vindas. Diálogos em tons cordiais são previstos em escritórios e ambientes similares de trabalho. Gritos, correrias e brincadeiras aparecem como hábitos correntes no pátio escolar durante o intervalo de aulas de uma unidade de educação infantil.

Conforme demonstrado na fundamentação teórica, os contextos onde se desenvolvem as interações face a face impõem diferentes graus de restrições. É provável que ambientes com barreiras físicas concretas e artificiais, como paredes, muros ou balcões, estabeleçam condições mais limitantes - porém seguras - para a comunicação. O ambiente visto como obstáculo talvez justifique uma percepção mais palpável do potencial constrangedor de algumas instalações. Por outro lado, espaços inseridos na natureza podem apresentar-se como cenários mais relaxantes e menos formais, onde possíveis tensões durante os diálogos seriam contidas pela própria intervenção da paisagem. É recomendável ampliar o conjunto de locais estudados para estabelecer, de forma mais sólida, essas relações.

Neste artigo foi possível observar que os ambientes físicos - e seus códigos mediadores - induzem a certos comportamentos e atitudes. Porém, também é perceptível que o espaço físico, por si só, repercute de maneira limitada sobre as

\footnotetext{
${ }^{9}$ Bebida semelhante ao chimarrão, mas feita com água fria.
} 
condutas. As formas de interação face a face são determinadas por uma coleção articulada de elementos contextuais, como o ambiente, as regras e costumes sociais, o tipo de relação entre interlocutores, o tempo, entre outros.

A discussão em torno das funções mediadoras dos espaços físicos levanta um debate vigoroso a respeito da intensificação do processo de midiatização na sociedade como um todo e em alguns espaços geográficos em particular. O trabalho de comunicação organizacional desenvolvido em regiões consideradas exóticas precisa levar em conta a evolução desse processo. O conhecimento das instâncias mediadoras desses ambientes será adquirido, em grande parte, por meio de tentativa e erro, pois a pesquisa em comunicação a respeito dessas condições contextuais é incipiente.

A discussão desenvolvida nestas páginas aponta a centralidade do ser humano inserido em um contexto social, demarcado por mediações e vivências. Investigadores que se aventuram por essa seara encaram ao menos dois desafios contundentes: a complexidade de articular os aspectos mediadores do contexto e a impossibilidade de se reproduzir as sensações vivenciadas durante as experiências (CARDOSO FILHO, 2008; QUÉRÉ, 2010; WOLTON, 2004).

Daí a relevância de metodologias como a imersão, apontada como caminho para exploração do espaço geográfico por Sandeville Junior (2004) e Sakaguti Junior (2010). Mesmo sabendo de antemão das dificuldades que enfrentará ao tentar descrever cientificamente sua experiência em determinado local, o pesquisador que optar pela vivência vai adquirir um conhecimento único e indispensável se quiser, de fato, desvendar o papel mediador dos ambientes nos processos comunicacionais.

\section{Referências}

BALOGH, Anna Maria. "Minha terra tem Pantanal, onde canta o tuiuiú...": a guerra de audiência na TV brasileira no início dos anos 90. In: SOUSA, Mauro Wilton de (Org. ). Sujeito, o lado oculto do receptor. São Paulo: Brasiliense, 2002. p. 135150.

BARROS, Manoel de. Livro de pré-coisas: roteiro para uma excursão poética no Pantanal. 2. ed. Rio de Janeiro: Record, 1997.

BIANCHI, Graziela. Considerações sobre processualidade metodológica e a relação pesquisador-pesquisado. In: MALDONADO, Alberto Efendy et al. Metodologias de pesquisa em comunicação: olhares, trilhas e processos. 2. ed. Porto Alegre: Sulina, 2011. p. 131-152.

CARDOSO FILHO, Jorge Luiz Cunha. A incidência dos conceitos de mediações e experiência no estudo da música popular massiva. In: PRIMO, Alex et al (Orgs.). 
Comunicação e interações: livro da Compós 2008. Porto Alegre: Sulina, 2008. p. 131-146.

DUTRA, Manuel José Sena. A Amazônia na TV: produção de sentido e o discurso da ecologia. In: XXIV CONGRESSO BRASILEIRO DA COMUNICAÇÃO, 2001, Campo Grande. Anais eletrônicos... Campo Grande: Intercom, 2001. Disponível em: <http://www. intercom. org. br/papers/nacionais/2001/papers/NP9DUTRA. PDF>.

Acesso em: 27 out. 2012. EDUFBA; Brasília: Compós, 2012, p. 31-52.

KUNSCH, Margarida Maria Krohling. Planejamento de relações públicas na comunicação integrada. 5. ed. São Paulo: Summus, 2003.

A dimensão humana da comunicação organizacional. In: KUNSCH, Margarida Maria Krohling (Org.). A comunicação como fator de humanização das organizações. São Caetano do Sul: Difusão, 2010. p. 41-60.

LIPPMANN, Walter. Opinião pública. 2. ed. Petrópolis: Vozes, 2010.

MACHADO, Arlindo; BECKER, Beatriz. Pantanal: a reinvenção da telenovela. São Paulo: Educ, 2008.

MAIO, Ana Maria Dantas de. Comunicação e representações sociais: o Pantanal que os brasileiros (des) conhecem. In: Estudos em Comunicação, Covilhã, n. 5, 217226, maio 2009.

MARTIN SERRANO, Manuel: Mediación. In: DEL CAMPO, Salustiano (Org.). Diccionario de ciências sociales. Madrid: Instituto de Estudios Políticos/Unesco, p. 179-184, 1976. Disponível em: http://eprints.ucm.es/10657/. Acesso em: 3 ago. 2014.

La estructura de la narración icónica en la televisión. Disertación magistral de Doctorado de Estado en Ciencias y Letras. In: Razón y Palabra, México, n. 72, p. 1-17, jul. 2010. Disponível em: http://www.razonypalabra.org.mx/N/N72/MMS/MMS_castellano_corr_72.pdf. Acesso em: 26 jun. 2015.

MARTINO, Luís Mauro Sá. Mediação e midiatização da religião em suas articulações teóricas e práticas: um levantamento de hipóteses e problemáticas. In: MATTOS, Maria Ângela; JANOTTI JR., Jeder; JACKS, Nilda (Orgs.). Mediação \& midiatização. Salvador: EDUFBA; Brasília: Compós, 2012. p. 219-244.

MARTINS, Marta Terezinha Motta Campos. Diálogo e interações face a face na comunicação interna: um estudo da oralidade nas organizações. 2012. Tese (Doutorado em Ciência da Comunicação) - Escola de Comunicação e Artes, Universidade de São Paulo, São Paulo, 2012.

MORAES, André Steffens. Percepções sobre a paisagem no Pantanal [mensagem pessoal]. Mensagem recebida por ana.maio@embrapa.br em 11 fev. 2014.

QUÉRÉ, Louis. O caráter impessoal da experiência. In: LEAL, Bruno Souza; MENDONÇA, Carlos Camargos; GUIMARÃES, César (Orgs.). Entre o sensível e o comunicacional. Belo Horizonte: Autêntica, 2010. p. 19-38. 
SAKAGUTI JUNIOR, Mário Masaru. Significados das paisagens da microbacia do ribeirão dos Sinos, I peuna, SP. 2010. Dissertação (Mestrado em Ciências) Universidade de São Paulo, Piracicaba, 2010. Disponível em: http://www.teses.usp.br/teses/disponiveis/91/91131/tde-20092010-140717/ptbr.php. Acesso em: 24 ago. 2013.

SANDEVILLE JUNIOR, Euler. Paisagens e métodos: algumas contribuições para elaboração de roteiros de estudo da paisagem intraurbana. In: Paisagens em Debate, São Paulo, n. 2, p. 1-6, set. 2004. Disponível em: http://www.usp.br/fau/depprojeto/gdpa/paisagens/inicio.html. Acesso em 23 jun. 2015.

SCHETTINO, Paulo Bráz Clemencio. Duas Amazônias. In: XXXVI CONGRESSO BRASILEIRO DE CIÊNCIAS DA COMUNICAÇÃO, 2013. Manaus. Anais eletrônicos... Manaus: Intercom/Ufam, 2013. Disponível em: http://www. intercom.org. br/papers/nacionais/2013/resumos/R8-1480-1. pdf.

Acesso em: 14 jul. 2015.

SCHUTZ, Alfred. O mundo das relações sociais. In: WAGNER, Helmut R. (Org.). Fenomenologia e relações sociais: textos escolhidos de Alfred Schutz. Rio de Janeiro: Zahar Editores, 1979. p. 157-237. Disponível em: https://www. passeidireto.com/arquivo/2295273/alfred-schutz---fenomenologia-erelacoes-sociais-livro. Acesso em: 27 nov. 2014.

VALENTE, Eduardo. Cabeça a Prêmio, de Marco Ricca (Brasil, 2009). In: Cinética, Rio de Janeiro, out. 2009. Disponível em: http://www.revistacinetica.com.br/cabecaapremio.htm. Acesso em: 14 jul. 2015.

WOLTON, Dominique. Pensar a comunicação. Brasília: Editora Universidade de Brasília, 2004. 